\title{
Delta spike P681R mutation enhances SARS-CoV-2 fitness over Alpha variant
}

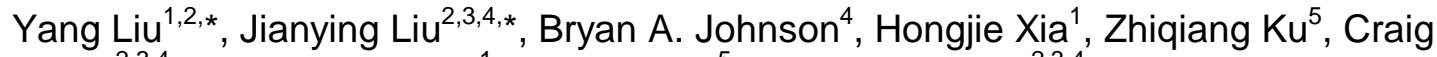 \\ Schindewolf ${ }^{2,3,4}$, Steven G. Widen ${ }^{1}$, Zhiqiang $\mathrm{An}^{5}$, Scott C. Weaver ${ }^{2,3,4}$, Vineet D. Menachery ${ }^{2,3,4}$, \\ Xuping Xie ${ }^{1 \#}$, and Pei-Yong Shi ${ }^{1,2,3, \#}$
}

${ }^{1}$ Department of Biochemistry and Molecular Biology, University of Texas Medical Branch, 7 Galveston TX, USA

$8{ }^{2}$ Institute for Human Infections and Immunity, University of Texas Medical Branch, Galveston 9 TX, USA

${ }^{3}$ World Reference Center for Emerging Viruses and Arboviruses, University of Texas Medical Branch, Galveston TX, USA

$12{ }^{4}$ Department of Microbiology and Immunology, University of Texas Medical Branch, Galveston 13 TX, USA

$14{ }^{5}$ Texas Therapeutics Institute, Brown Foundation Institute of Molecular Medicine, The University of Texas Health Science Center at Houston, Houston, TX 77030, USA

${ }^{*} \mathrm{YL}$ and $\mathrm{JL}$ made equal contributions to the study

\#Correspondence: X.X. (xuxie@UTMB.edu) or P.-Y.S. (peshi@UTMB.edu)

\section{Abstract}

SARS-CoV-2 Delta variant has rapidly replaced the Alpha variant around the world. The mechanism that drives this global replacement has not been defined. Here we report that Delta spike mutation P681R plays a key role in the Alpha-to-Delta variant replacement. In a replication competition assay, Delta SARS-CoV-2 efficiently outcompeted the Alpha variant in human lung epithelial cells and primary human airway tissues. Delta SARS-CoV-2 bearing the Alpha-spike

27 glycoprotein replicated less efficiently than the wild-type Delta variant, suggesting the 28 importance of Delta spike in enhancing viral replication. The Delta spike has accumulated 29 mutation P681R located at a furin cleavage site that separates the spike 1 (S1) and S2 30 subunits. Reverting the P681R mutation to wild-type P681 significantly reduced the replication 
31 of Delta variant, to a level lower than the Alpha variant. Mechanistically, the Delta P681R

32 mutation enhanced the cleavage of the full-length spike to S1 and S2, leading to increased

33 infection via cell surface entry. In contrast, the Alpha spike also has a mutation at the same

34 amino acid $(\mathrm{P} 681 \mathrm{H})$, but the spike cleavage from purified Alpha virions was reduced compared

35 to the Delta spike. Collectively, our results indicate P681R as a key mutation in enhancing Delta

36 variant replication via increased S1/S2 cleavage. Spike mutations that potentially affect furin

37 cleavage efficiency must be closely monitored for future variant surveillance.

\section{Introduction}

The continuous emergence of new variants of severe acute respiratory syndrome

41 coronavirus 2 (SARS-CoV-2) poses the greatest threat to pandemic control, vaccine

42 effectiveness, therapeutic efficacy, and surveillance. Since its emergence in late 2019,

43 mutations have unceasingly emerged in the circulating viruses, leading to variants with

44 enhanced transmissibility, evasion of therapeutic antibodies, and breakthrough infections in

45 vaccinated individuals. ${ }^{1-6}$ Since the viral spike glycoprotein is responsible for binding to the

46 human cellular receptor angiotensin-converting enzyme (ACE2), many mutations have

47 accumulated in the spike gene with the potential to alter viral fitness or to escape immunity. The

48 variants have emerged from different geographic regions and, depending on their biological

49 properties, spread to other regions. The World Health Organization (WHO) has classified

50 variants as "variants of concern" (i.e., Alpha, Beta, Gamma, and Delta) and "variants of interest"

51 (i.e., Eta, lota, Kappa, and Lambda). ${ }^{7}$ The Alpha variant was first identified in the United

52 Kingdom in September 2020 and subsequently became dominant in many parts of the world.

53 Afterwards, the Delta variant emerged in India in October 2020 and has now spread to over 119

54 countries, displacing the Alpha variant globally. ${ }^{7,8}$ From May 2 to July 31 of 2021 , the

55 prevalence of the Delta variant in the USA had increased from $1.3 \%$ to $94.4 \%$, whereas the 
56 prevalence of the Alpha variant had decreased from $70 \%$ to $2.4 \%$. More seriously, the Delta

57 variant has been associated with increased transmissibility, disease severity, and breakthrough

58 infections in vaccinated individuals., ${ }^{5-11}$ The mutation(s) that have driven the explosive spread

59 of the Delta variant and its displacement of the Alpha variant remain to be defined. In this study,

60 we used a reverse genetic approach to identify the molecular determinant(s) for the enhanced

61 fitness of Delta variant and its dominance over the Alpha variant.

We constructed infectious cDNA clones for the Alpha (GISAIS ID: EPI_ISL_999340) and Delta (GISAIS ID: EPI_ISL_2100646) SARS-CoV-2 variants using a previously established protocol (Extended data Fig. 1). ${ }^{12,13}$ The infectious cDNA clones enabled us to prepare recombinant Alpha and Delta SARS-CoV-2 variants (Fig. 1a). Both Alpha and Delta variants rescued from these clones developed smaller plaques on Vero E6 cells than the earlier USA/WA1-2020 (wild-type) strain isolated in January 2020 (Extended data Fig. 2). Sequencing analysis showed no undesired mutations in the rescued recombinant virus stocks. To compare the viral replication fitness between the Alpha and Delta variants, we performed a competition assay by infecting cells with a mixture of the two viruses at a plaque-forming unit (PFU) ratio of $1: 1$, followed by quantifying the ratios of the two viral RNA species at different days post infection. Compared with analyzing individual viruses separately, the competition assay has the advantages of (i) a built-in internal control of each viral replication and (ii) elimination of host-tohost variation that reduces experimental power. Due to its precision and reproducibility ${ }^{14}$, the competition assay has been widely used to study microbial fitness, ${ }^{15-17}$ including SARS-CoV$2^{1,18}$. When infecting human lung adenocarcinoma Calu-3 cells, the RNA ratio of Delta versus Alpha increased to 3.0, 7.0, and 4.1 at 24, 36, and 48 h post infection, respectively (Extended 
Delta versus Alpha increased from 1.7 on day 1 to 3.1 on day 5 (Fig. 1b). These results indicate

82 that Delta variant has greater replication fitness compared to the Alpha variant in in vitro

83 respiratory models of SARS-CoV-2 infection.

To examine if the spike gene alone determines the improved replication fitness of the Delta variant, we constructed a chimeric Delta SARS-CoV-2 bearing the Alpha-spike glycoprotein (i.e., Alpha-spike/Delta-backbone virus; Fig. 1a and Extended data Fig. 2b). In a competition assay on HAE culture, the RNA ratio of Delta versus Alpha-spike/Delta-backbone continuously increased from 2.8 on day 1 to 9.8 on day 5 post infection (Fig. 1C), suggesting that (i) the Alpha-spike reduces the replication fitness of the Delta variant and (ii) the spike gene drives the improved replication of Delta variant. Interestingly, the Alpha-spike/Delta-backbone virus replicated less efficiently than the Alpha variant on HAE culture (Fig. 1d), suggesting that,

92 in contrast to Delta spike mutations that enhance replication, mutations outside the spike gene of the Delta variant reduced to some degree fitness for viral replication. The above quantifications of viral competition outcomes were measured by Sanger sequencing (Fig. 1b-d) and subsequently verified by Illumina next generation sequencing (NGS; Extended data Fig. 4).

Delta spike has accumulated mutations T19R, G142D, E156G, F157-R158 deletion, L452R, T478K, D614G, P681R, and D950N, ${ }^{19}$ among which P681R is located at a furin cleavage site (PRRAR $\downarrow S$ with P681 underlined and " $\downarrow$ " indicating furin cleavage) that is absent in other group $2 \mathrm{~B}$ coronaviruses. ${ }^{20}$ Since the furin cleavage site was shown to be important for SARS-CoV-2 replication and pathogenesis, ${ }^{21,22}$ we hypothesized that mutation P681R may improve the furin cleavage efficiency of full-length spike to $S 1$ and S2, leading to a more efficient virus entry into respiratory epithelial cells. To test this hypothesis, we reverted the Delta P681R mutation to wild-type P681 in the Delta SARS-CoV-2 (Extended data Fig. 2a). The 
106

107

108

109

110

111

112

114

115

116

117

118

119

120

121

122

123

124

125

data Fig. 2b). Remarkably, the P681 reversion attenuated Delta variant replication on HAE cultures, as evidenced by the increase in the RNA ratio of wild-type Delta versus Delta-P681 from 2.2 on day 1 to 3.4 on day 5 (Fig. 1e). The replication of the Delta-P681 virus was even lower than that of the Alpha variant, as suggested by the decrease in the RNA ratio of DeltaP681 versus Alpha variant from 0.9 on day 1 to 0.6 on day 5 (Fig. 1f). These results demonstrate that mutation P681R at the furin cleavage site plays a critical role in enhancing the replication of the Delta variant on primary human airway cultures.

We directly evaluated the spike cleavage of Alpha, Delta, Delta-P681, and wild-type SARS-CoV-2. Virions were prepared from Vero E6 cells expressing TMPRSS2, a host serine protease that is required for SARS-CoV-2 entry via the ACE2-mediated cell surface mechanism. ${ }^{23}$ After virions were purified through sucrose cushion ultracentrifugation, pelleted viruses were analyzed for spike cleavage by Western blotting (Fig. 19). The results showed that spike processing efficiency of the purified virions occurred in the order of Delta > Alpha > DeltaP681 > wild-type virions, with ratios of S1 versus full-length spike of $15.3,5.4,2.7$, and 1.4, respectively (Fig. 1h). It should be noted that the Alpha variant also has a spike mutation at amino acid position $681(\mathrm{P} 681 \mathrm{H})$, which may contribute to the increase in spike cleavage when compared with the wild-type USA/WA1-2020 virus; however, a recent study showed that mutation $\mathrm{P} 681 \mathrm{H}$ alone did not enhance viral fitness or transmission. ${ }^{4}$ Overall, our results indicate a correlation of improved spike cleavage with enhanced viral replication of Delta variant.

To exclude the possibility that enhanced replication of the Delta variant over Alpha was due to an improved spike/ACE2 receptor interaction, we performed a binding assay using recombinant spike receptor-binding domain $(\mathrm{RBD})$ and human ACE2 proteins on a Bio-Layer Interferometry (BLI) system (Extended data Fig. 5). Within the RBD, the Alpha RBD has a N501Y mutation, whereas Delta RBD has L452R and T478K mutations. The BLI results indicate 
131 that the Alpha RBD has a higher binding affinity for ACE2 than Delta RBD, as indicated by

$132>200$-fold $K_{D}$ improvement (Extended data Fig. 5). These data strongly argue that the higher

133 replication of Delta variant than Alpha variant is not due to an improved spike/ACE2 receptor 134 binding.

\section{Discussion}

fitness and transmission. First, it accumulated a D614G mutation in the spike gene to enhance viral transmission. ${ }^{1,3,6,24}$ This mutation promotes spike RBD in an "open" conformation to

140 facilitate ACE2 receptor binding. ${ }^{25}$ Subsequently, another spike mutation N501Y emerged 141 independently in Alpha, Beta, and Gamma variants from the United Kingdom, South Africa, and

142 Brazil, respectively. The N501Y mutation further increases the binding affinity between the spike 143 protein and ACE2, leading to additional improvement in viral transmission. ${ }^{4,10,26}$ Most recently, 144 the Delta variant emerged and spread explosively, replacing the Alpha variant around the world. 145 The current study demonstrates that spike mutation(s) are responsible for the enhanced viral 146 fitness of the Delta variant over Alpha. Importantly, the unique P681R mutation plays a critical 147 role in this fitness advantage and increases the processing of Delta spike to S1 and S2, most 148 likely through an improved furin cleavage when newly assembled virions egress through the 149 trans-Golgi network. Although the original SARS-CoV-2 strain has a functional furin cleavage 150 site with a minimal recognition site of $\mathrm{RXXR} \downarrow,{ }^{27}$ adjacent residues influence the cleavage 151 efficiency. ${ }^{28}$ The P681R substitution clearly augments spike processing and is likely the main 152 driver of the fitness advantage observed in Delta variant. When the Delta variant infects 153 respiratory epithelial cells, it binds to ACE2 receptor via the RBD in S1. Already cleaved at the 154 S1/S2 site, the Delta virion facilitates cleavage at S2' by the cell surface protease TMPRSS2, 155 leading to an activation of the S2 fusion peptide (FP) for viral and plasma membrane fusion. ${ }^{23}$ 
156 Thus, the improved spike cleavage enhances viral replication when the Delta variant infects 157 respiratory epithelial cells.

One major concern with the emergence of Delta variant is its association with increased breakthrough infections in vaccinated people. ${ }^{5,9}$ As a critical target for host immunity, changes in 160 the spike protein of SARS-CoV-2 variants have been implicated in reducing antibody 161 neutralization. ${ }^{29}$ Among all tested variants (including Delta), the Beta and Kappa variants have 162 been shown to reduce the BNT162b2 vaccine-elicited neutralizing titers the most; ${ }^{2,30-32}$ yet, BNT162b2 showed 100\% vaccine efficacy against Beta variant-associated severe, critical or fatal disease in Qatar and 100\% real-world effectiveness against Beta variant-associated COVID-19 in South Africa. ${ }^{33,34}$ These real-world vaccine efficacy/effectiveness and in vitro neutralization results argue that breakthrough infections by the Delta variant in vaccinated individuals do not reflect immune escape. Instead, the increased breakthrough infection is likely due to enhanced viral replication fitness of the Delta variant through augmented spike processing. Consistent with this hypothesis, the viral RNA loads in the oropharynx from Delta variant-infected patients were $>1,200$-fold higher than those from the original Wuhan virus-

171 infected patients. ${ }^{9}$ Together, the results indicate changes in viral processing and infection 172 efficiency, rather than evasion of antibodies, drive breakthrough infections of Delta variant in 173 vaccinated individuals.

In summary, using a reverse genetic system and primary human airway cultures, we have identified spike mutation P681R as a significant determinant for enhanced viral replication fitness of the Delta compared to the Alpha variant. The P681R mutation enhances spike protein 177 processing through the improved furin cleavage site. As new variants continue to emerge, spike mutations that affect furin cleavage efficiency, as well as other mutations that may increase viral replication, pathogenesis, and/or immune escape, must be closely monitored. 


\section{Methods}

Cells. African green monkey kidney epithelial Vero E6 cells (ATCC, Manassas, VA, USA) were grown in Dulbecco's modified Eagle's medium (DMEM; Gibco/Thermo Fisher, Waltham, MA, USA) with 10\% fetal bovine serum (FBS; HyClone Laboratories, South Logan,

UT) and 1\% penicillin/streptomycin (Gibco). Human lung adenocarcinoma epithelial Calu-3 cells

length (FL) cDNA clones of Alpha and Delta variants were constructed through mutagenesis of

data Fig. 1a) to construct the full-length cDNA clones of Alpha and Delta SARS-CoV-2, resulting in Alpha-FL and Delta-FL, respectively. Prior to the three-fragment ligation, mutations spike/Delta-backbone were downloaded from GISAID database, the accession ID for Alpha is

202 EPI_ISL_999340, accession ID for Delta is EPI_ISL_2100646. Individual point mutations for 203 Alpha (NSP3: P153L, T183I, A890D, I1412T; NSP6: SGF106-108del; NSP12: P323L; Spike: 204 HV69-70del, Y145del, N501Y, A570D, D614G, P681H, T716I, S982A, D1118H; ORF8: 205 Q27stop, R52I, Y73C, S84L; N: D3L, R203K, G204R, S235F) and individual point mutations for 
Delta (NSP2: P129L; NSP3: P822L; H1274Y; NSP4: A446V; NSP6: V149A; NSP12: P323L; V355A; G671S; NSP13: P77L; NSP15: H234Y; Spike: T19R, G142D, E156G, FR157-158del, L452R, T478K, D614G, P681R, D950N; ORF3a: S26L; M: I82T; ORF7a: V82A; L116F; T120I; ORF8: S84L; DF119-120del; N: D63G; R203M; D377Y; R385K) were introduced into subclones of individual fragments by overlapping fusion PCR. For preparing Alpha-spike/Delta-backbone virus, the spike gene of Delta was replaced with the spike gene of the Alpha. For preparing Delta-P681 virus, the P681 reversion was introduced into a subclone containing Delta spike gene by overlapping fusion PCR. All primers used for the construction were listed in Extended

214 Data Table 1. The full-length infectious clones of SARS-CoV-2 variants were assembled by in 215 vitro ligation of contiguous DNA fragments. In vitro transcription was then performed to synthesize full-length genomic RNA. For recovering recombinant viruses, the RNA transcripts were electroporated into Vero E6 cells. The viruses from electroporated cells were harvested at $40 \mathrm{~h}$ post electroporation and served as P0 stocks. All viruses were passaged once on Vero E6 cells to produce P1 stocks for subsequent experiments. All P1 viruses were subjected to next generation sequencing to confirm the introduced mutations without undesired changes. Viral

221 titers were determined by plaque assay on Vero E6 cells. All virus preparation and experiments were performed in a biosafety level 3 (BSL-3) facility. Viruses and plasmids are available from the World Reference Center for Emerging Viruses and Arboviruses (WRCEVA) at the University of Texas Medical Branch.

RNA extraction, RT-PCR, and Sanger sequencing. Cell culture supernatants were 226 mixed with a five-fold excess of TRIzol ${ }^{\mathrm{TM}}$ LS Reagent (Thermo Fisher Scientific, Waltham, MA, 227 USA). Viral RNAs were extracted according to the manufacturer's instructions. The RNAs were 228 amplified using a SuperScript ${ }^{\mathrm{TM}}$ III One-Step RT-PCR kit (Invitrogen, Carlsbad, CA, USA) 229 following the manufacturer's protocol. The size of desired amplicon was verified with $2 \mu$ of 230 PCR product on an agarose gel. The remaining $18 \mu$ of RT-PCR DNA was purified by a 
231 QIAquick PCR Purification kit (Qiagen, Germantown, MD, USA). Sequences of the purified RT-

232 PCR products were generated using a BigDye Terminator v3.1 cycle sequencing kit (Applied

233 Biosystems, Austin, TX, USA). The sequencing reactions were purified using a 96-well plate

234 format (EdgeBio, San Jose, CA, USA) and analyzed on a 3500 Genetic Analyzer (Applied

235 Biosystems, Foster City, CA). The peak electropherogram height representing each mutation

236 site and the proportion of each competitor was analyzed using the QSVanalyser program. For

237 the competition assay, R software is used for the figure generation and statistical analysis. The

238 presented viral RNA ratios in the figures were normalized by the input viral RNA ratios

239 (Extended Data Table 2).

Plaque assay. Approximately $1.2 \times 10^{6}$ Vero E6 cells were seeded to each well of 6 -well

241 plates and cultured at $37^{\circ} \mathrm{C}, 5 \% \mathrm{CO}_{2}$ for $16 \mathrm{~h}$. Virus was serially diluted in DMEM with $2 \%$ FBS

242 and $200 \mu \mathrm{l}$ diluted viruses were transferred onto the cell monolayers. The viruses were

243 incubated with the cells at $37^{\circ} \mathrm{C}$ with $5 \% \mathrm{CO}_{2}$ for $1 \mathrm{~h}$. After the incubation, overlay medium was

244 added to the infected cells per well. The overlay medium contained DMEM with $2 \%$ FBS, $1 \%$

245 penicillin/streptomycin, and 1\% sea-plaque agarose (Lonza, Walkersville, MD). After 2.5-day

246 incubation, plates were stained with neutral red (Sigma-Aldrich, St. Louis, MO, USA) and

247 plaques were counted on a light box.

Next generation sequencing (NGS). The competition results generated by Sanger sequencing were confirmed using NGS methods. Briefly, viral RNA samples from competition groups of (i) Delta versus Alpha and (ii) Delta versus Alpha-spike/Delta-backbone were used for a specific one-step RT-PCR that containing the A23063T mutation site. Viral RNA samples from competition group of Alpha versus Alpha-spike/Delta-backbone were quantified by the T14444C mutation. The RT-PCR primers were listed in Extended Data Table 1. The PCR products were 254 purified by a QIAquick PCR Purification kit (Qiagen, Germantown, MD) according to the 255 manufacturer's protocol. Dual-indexed adapter sequences (New England BioLabs, Ipswich, MA) 
were added with 5 cycles of PCR. Samples were pooled and sequenced on an Illumina MiniSeq Mid-Output flow cell with the paired-end 150 base protocol. The reads were filtered for Q-scores of 37 at the A23063T and T14444C mutation sites and adjacent bases and counted. For the competition assay, R software is used for the figure generation and statistical analysis.

Viral infection of cell lines. Approximately $3 \times 10^{5}$ Calu-3 cells were seeded onto each well of 12-well plates and cultured at $37^{\circ} \mathrm{C}, 5 \% \mathrm{CO}_{2}$ for $16 \mathrm{~h}$. Equal PFUs of two viruses were inoculated onto Calu- 3 cells at a final $\mathrm{MOI}$ of 0.1 . The mixed viruses were incubated with the cells at $37^{\circ} \mathrm{C}$ for $2 \mathrm{~h}$. After infection, the cells were washed thrice with DPBS to remove residual viruses. One milliliter of culture medium was added into each well. At each time point, $100 \mu \mathrm{l}$ of analysis.

Primary human airway cultures. The EpiAirway system is a primary human airway 3D mucociliary tissue model consisting of normal, human-derived tracheal/bronchial epithelial cells.

271 Different combinations of mixed viruses for competition assays were inoculated onto the culture at a total $\mathrm{MOI}$ of 5 . After $2 \mathrm{~h}$ infection at $37^{\circ} \mathrm{C}$ with $5 \% \mathrm{CO}_{2}$, the inoculum was removed, and the culture was washed three times with DPBS. The infected epithelial cells were maintained without any medium in the apical well, and medium was provided to the culture through the basal well. The infected cells were incubated at $37^{\circ} \mathrm{C}, 5 \% \mathrm{CO}_{2}$. From day 1 to day 5 post infection, $300 \mu$ of DPBS were added onto the apical side of the airway culture and incubated at

$27737^{\circ} \mathrm{C}$ for $30 \mathrm{~min}$ to elute progeny viruses. All virus samples in DPBS were stored at $-80^{\circ} \mathrm{C}$ and quantified by plaque assays on Vero E6 cells. 
281

282

283

284

285

286

287

288

289

290

291

292

293

294

295

296

medium was collected, purified through a $20 \%$ sucrose cushion, and analyzed by Western blot as previously described. ${ }^{21}$ Densitometry was performed to quantify the cleavage efficiency of full-length spike to S1/S2 subunits using ImageLab 6.0.1 (Bio-Rad \#12012931). The average results of two experiments were presented.

Spike RBD and ACE2 binding. The human ACE2 protein was purchased from Sino Biological (Beijing, China; Cat\# 10108-H08H) and the human IgG1 Fc-tagged RBD proteins were made in-house using a method as previously described ${ }^{35}$. The affinity measurement was performed on the ForteBio Octet RED 96 system (Sartorius, Goettingen, Germany). Briefly, the RBD proteins $(20 \mu \mathrm{g} / \mathrm{ml})$ of Alpha or Delta RBDs were captured onto protein A biosensors for 300s. The loaded biosensors were then dipped into the kinetics buffer for $10 \mathrm{~s}$ for adjustment of baselines. Subsequently, the biosensors were dipped into serially diluted (from 1.23 to $300 \mathrm{nM}$ ) human ACE2 protein for $200 \mathrm{~s}$ to record association kinetics and then dipped into kinetics buffer for $400 \mathrm{~s}$ to record dissociation kinetics. Kinetic buffer without ACE2 was used to correct the background. The Octet Data Acquisition 9.0 software was used to collect affinity data. For fitting of $K_{D}$ values, Octet Data Analysis software V11.1 was used to fit the curve by a $1: 1$ binding model using the global fitting method.

Statistics. For virus competition experiments, relative replicative fitness values for different variants were analyzed according to $\mathrm{w}=(\mathrm{fO} / \mathrm{i} 0)$, where i0 is the initial two-virus ratio and f0 is the final two-virus ratio after competition. Sanger sequencing (initial timepoint T0) counts for each virus being compared were based upon average counts over three replicate samples of inocula per experiment, and post-infection (timepoint T1) counts were taken from samples of individual subjects. Multiple experiments were performed, so that f0/i0 was clustered by experiment. To model f0/i0, the ratio T0/T1 was found separately for each subject in each virus group, log (base-10) transformed to an improved approximation of normality and modeled by analysis of variance with relation to group, adjusting by experiment when appropriate to control 
306 for clustering within experiment. Specifically, the model was of the form

307 Log10_CountT1overCountT0 Experiment + Group. Fitness ratios between the two groups [the

308 model's estimate of $\mathrm{w}=(\mathrm{f0} / \mathrm{i} 0)$ ] were assessed per the coefficient of the model's Group term,

309 which was transformed to the original scale as $10^{\wedge}$ coefficient. This modeling approach

310 compensates for any correlation due to clustering within experiment similarly to that of

311 corresponding mixed effect models and is effective since the number of experiments was small.

312 Statistical analyses were performed using R statistical software (R Core Team, 2019, version

313 3.6.1). In all statistical tests, two-sided alpha $=.05$. Catseye plots ${ }^{36}$, which illustrate the normal

314 distribution of the model-adjusted means, were produced using the "catseyes" package ${ }^{37}$.

Data availability.

Extended Data and source data for generating main figures are available in the online version of the paper. Any other information is available upon request.

\section{Acknowledgments}

323 John S. Dunn Foundation, the Amon G. Carter Foundation, the Gillson Longenbaugh

324 Foundation, and the Summerfield Robert Foundation. Z.A. was supported in by a Welch

325 Foundation grant AU-0042-20030616 and Cancer Prevention and Research Institute of Texas

326 (CPRIT) Grants RP150551 and RP190561. S.C.W. was supported by NIH grant R24 Al120942.

327 V.D.M. was supported by NIH grants Al153602 and 1R21Al145400. J.L. and B.A.J. were

328 supported by James W. McLaughlin Fellowship Fund. 


\section{Author contributions} P.-Y.S.

\section{Competing financial interests}

SARS-CoV-2. Other authors declare no competing interests.

\section{References}

Plante, J. A. et al. Spike mutation D614G alters SARS-CoV-2 fitness. Nature 592, 116-121, doi:10.1038/s41586-020-2895-3 (2021). Chen, R. E. et al. Resistance of SARS-CoV-2 variants to neutralization by monoclonal and serumderived polyclonal antibodies. Nat Med 27, 717-726, doi:10.1038/s41591-021-01294-w (2021).

3 Hou, Y. J. et al. SARS-CoV-2 D614G variant exhibits efficient replication ex vivo and transmission in vivo. Science 370, 1464-1468, doi:10.1126/science.abe8499 (2020).

4 Liu, Y. et al. The N501Y spike substitution enhances SARS-CoV-2 transmission. bioRxiv, doi:10.1101/2021.03.08.434499 (2021).

5 Brown, C. M. et al. Outbreak of SARS-CoV-2 Infections, Including COVID-19 Vaccine Breakthrough Infections, Associated with Large Public Gatherings - Barnstable County, Massachusetts, July 2021. Morbidity and Mortality Weekly Report (MMWR), https://www.cdc.gov/mmwr/volumes/70/wr/mm7031e7032.htm?s cid=mm7031e7032 w\&fbc lid=IwAR7032WV7036ul A-I VN 7015KX7034bedb7038CeLJKRwiDWZblUuWmZMKbs7094xdhTiPLs (2021). 
3586 Zhou, B. et al. SARS-CoV-2 spike D614G change enhances replication and transmission. Nature 592, 122-127, doi:10.1038/s41586-021-03361-1 (2021).

7 WHO. Track SARS-CoV-2 variants. https://www.who.int/en/activities/tracking-SARS-CoV-2variants/ (2021).

8 CDC. COVID data tracker. https://covid.cdc.gov/covid-data-tracker/\#variant-proportions (2021).

$9 \quad \mathrm{Li}, \mathrm{B}$. et al. Viral infection and transmission in a large, well-traced outbreak caused by the SARSCoV-2 Delta variant. medRxiv, https://www.medrxiv.org/content/10.1101/2021.1107.1107.21260122v21260122 (2021).

10 Mlcochova, P. et al. SARS-CoV-2 B.1.617.2 Delta variant emergence, replication and sensitivity to neutralising antibodies. BioRxiv (2021).

11 Chia, P. Y. et al. Virological and serological kinetics of SARS-CoV-2 Delta variant vaccine2 breakthrough infections: a multi-center cohort study. medRxiv, https://www.medrxiv.org/content/10.1101/2021.1107.1128.21261295v21261291 (2021).

12 Xie, X. et al. An Infectious cDNA Clone of SARS-CoV-2. Cell Host Microbe 27, 841-848 e843, doi:10.1016/j.chom.2020.04.004 (2020).

13 Xie, X. et al. Engineering SARS-CoV-2 using a reverse genetic system. Nature Protocols 16, 17611784, doi:10.1038/s41596-021-00491-8 (2021).

14 Liu, J. et al. Role of mutational reversions and fitness restoration in Zika virus spread to the Americas. Nat Commun 12, 595, doi:10.1038/s41467-020-20747-3 (2021).

15 Wiser, M. J. \& Lenski, R. E. A Comparison of Methods to Measure Fitness in Escherichia coli. PLoS One 10, e0126210, doi:10.1371/journal.pone.0126210 (2015).

16 Grubaugh, N. D. et al. Genetic Drift during Systemic Arbovirus Infection of Mosquito Vectors Leads to Decreased Relative Fitness during Host Switching. Cell Host Microbe 19, 481-492, doi:10.1016/j.chom.2016.03.002 (2016).

17 Bergren, N. A. et al. "Submergence" of Western equine encephalitis virus: Evidence of positive selection argues against genetic drift and fitness reductions. PLoS Pathog 16, e1008102, doi:10.1371/journal.ppat.1008102 (2020).

18 Touret, F. et al. Replicative Fitness of a SARS-CoV-2 20I/501Y.V1 Variant from Lineage B.1.1.7 in Human Reconstituted Bronchial Epithelium. mBio, e0085021, doi:10.1128/mBio.00850-21 (2021).

19 Organization, W. H. Coronavirus Disease (COVID-19): Weekly Epidemiological Update. https://reliefweb.int/report/world/coronavirus-disease-covid-19-weekly-epidemiologicalupdate-11-may-2021 (2021).

20 Coutard, B. et al. The spike glycoprotein of the new coronavirus 2019-nCoV contains a furin-like cleavage site absent in CoV of the same clade. Antiviral Res 176, 104742, doi:10.1016/j.antiviral.2020.104742 (2020).

21 Johnson, B. A. et al. Loss of furin cleavage site attenuates SARS-CoV-2 pathogenesis. Nature 591, 293-299, doi:10.1038/s41586-021-03237-4 (2021).

22 Peacock, T. P. et al. The furin cleavage site in the SARS-CoV-2 spike protein is required for transmission in ferrets. Nat Microbiol 6, 899-909, doi:10.1038/s41564-021-00908-w (2021).

23 Murgolo, N. et al. SARS-CoV-2 tropism, entry, replication, and propagation: Considerations for drug discovery and development. PLoS Pathog 17, e1009225, doi:10.1371/journal.ppat.1009225 (2021).

24 Korber, B. et al. Tracking Changes in SARS-CoV-2 Spike: Evidence that D614G Increases Infectivity of the COVID-19 Virus. Cell 182, 812-827 e819, doi:10.1016/j.cell.2020.06.043 (2020). 25 Yurkovetskiy, L. et al. Structural and Functional Analysis of the D614G SARS-CoV-2 Spike Protein Variant. Cell 183, 739-751, doi:10.1016/j.cell.2020.09.032 (2020). 
Wan, Y., Shang, J., Graham, R., Baric, R. S. \& Li, F. Receptor Recognition by the Novel Coronavirus from Wuhan: an Analysis Based on Decade-Long Structural Studies of SARS Coronavirus. $J$ Virol 94, doi:10.1128/JVI.00127-20 (2020).

27 Molloy, S. S., Bresnahan, P. A., Leppla, S. H., Klimpel, K. R. \& Thomas, G. Human furin is a calcium-dependent serine endoprotease that recognizes the sequence Arg-X-X-Arg and efficiently cleaves anthrax toxin protective antigen. Journal of Biological Chemistry 267, 1639616402 (1992).

28 Krysan, D. J., Rockwell, N. C. \& Fuller, R. S. Quantitative characterization of furin specificity. Energetics of substrate discrimination using an internally consistent set of hexapeptidyl methylcoumarinamides. J Biol Chem 274, 23229-23234, doi:10.1074/jbc.274.33.23229 (1999).

29 Plante, J. A. et al. The variant gambit: COVID-19's next move. Cell Host Microbe 29, 508-515, doi:10.1016/j.chom.2021.02.020 (2021).

30 Liu, Y. et al. Neutralizing Activity of BNT162b2-Elicited Serum. N Engl J Med 384, 1466-1468, doi:10.1056/NEJMc2102017 (2021).

31 Liu, Y. et al. BNT162b2-Elicited Neutralization against New SARS-CoV-2 Spike Variants. N Engl J Med, doi:10.1056/NEJMc2106083 (2021).

32 Liu, J. et al. BNT162b2-elicited neutralization of B.1.617 and other SARS-CoV-2 variants. Nature, doi:10.1038/s41586-021-03693-y (2021).

33 Abu-Raddad, L. J., Chemaitelly, H., Butt, A. A. \& National Study Group for, C.-V. Effectiveness of the BNT162b2 Covid-19 Vaccine against the B.1.1.7 and B.1.351 Variants. N Engl J Med 385, 187189, doi:10.1056/NEJMc2104974 (2021).

34 Thomas, S. J. et al. Six Month Safety and Efficacy of the BNT162b2 mRNA COVID-19 Vaccine. $N$ Engl J Med In press (2021).

$35 \mathrm{Ku}, \mathrm{Z}$. et al. Molecular determinants and mechanism for antibody cocktail preventing SARS-CoV2 escape. Nat Commun 12, 469, doi:10.1038/s41467-020-20789-7 (2021).

36 Cumming, G. The New Statistics: Why and How. Psychol. Sci., 7-29, doi:10.1177/0956797613504966 (2014).

37 Andersen, C. Catseyes: Create Catseye Plots Illustrating the Normal Distribution of the Means. $R$ package version 0.2.3. (2019). 

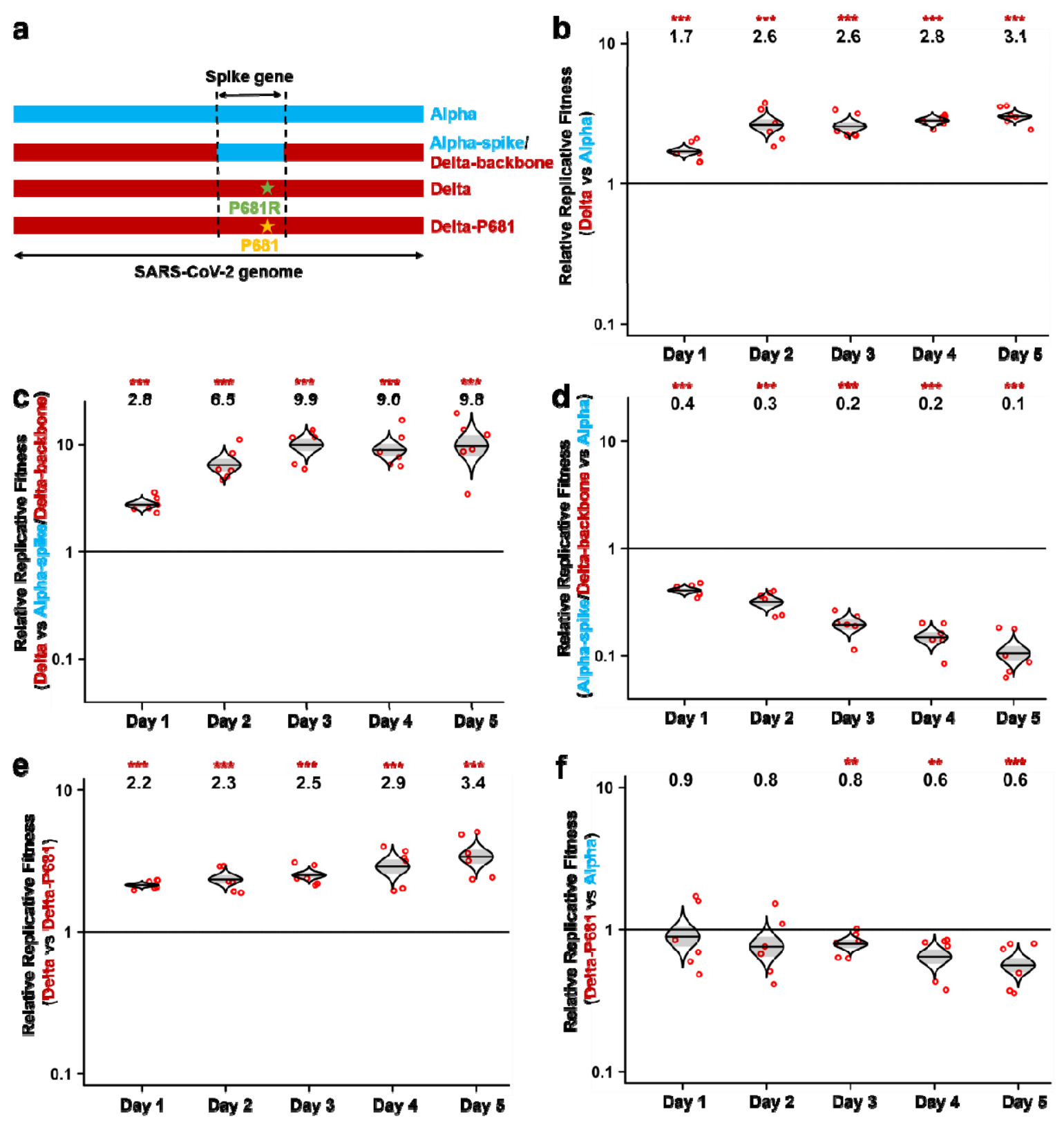

g

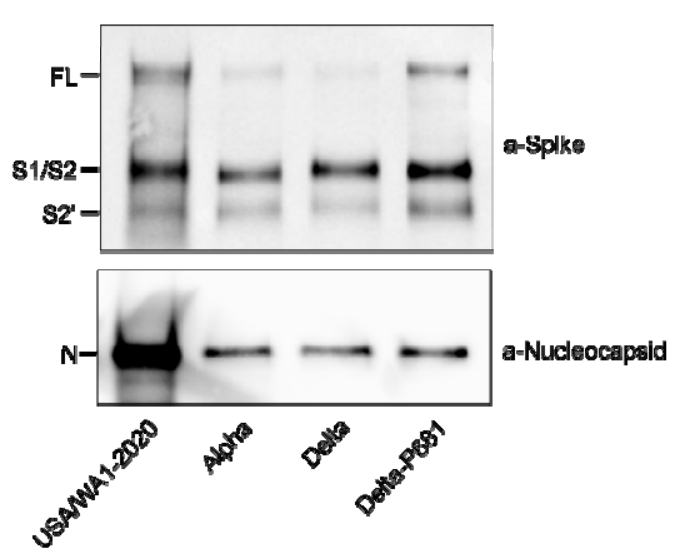

h

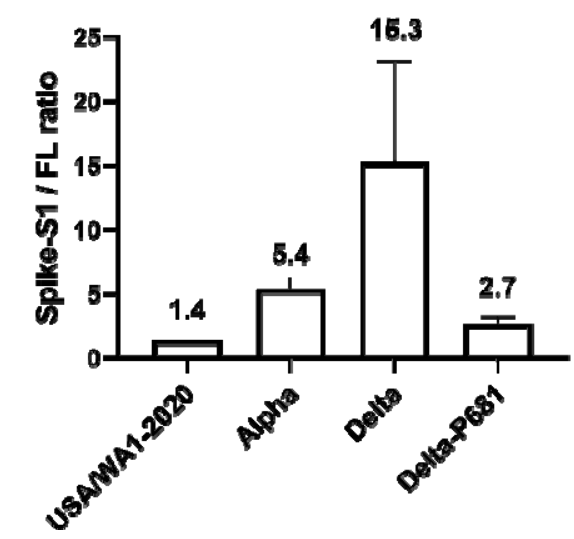


Figure 1. Delta P681R mutation enhances SARS-CoV-2 fitness over Alpha variant through improving spike protein processing.

a, Schemes of Alpha variant, Delta variant, Delta variant bearing Alpha-spike, and Delta variant with a P681R-to-P681 reversion. The spike gene of Delta variant was swapped with Alpha variant, resulting in chimeric SARS-CoV-2 "Alpha-spike/Delta-backbone." The Delta P681R mutation was reverted wild-type P681, resulting in "Delta-P681" virus. Blue and red colors indicate Alpha and Delta variants, respectively. b-f, Viral replication competitions among Alpha, Delta, Alpha-spike/Delta-backbone, and Delta-P681 viruses on primary human airway epithelial (HAE) cells. Equal PFU of two viruses were mixed and inoculated onto HAE cells at an MOI of 5. Five pairs of viral competition are presented: Delta and Alpha (b), Delta and Alpha-spike/Deltabackbone (c), Alpha-spike/Delta-backbone and Alpha (d), Delta variant and Delta-P618 (e), and Delta-P681 and Alpha (f). After $2 \mathrm{~h}$ incubation, the cells were washed thrice with DPBS and maintained for 5 days. The secreted viruses were collected daily in DPBS after incubation at $37^{\circ} \mathrm{C}$ for $30 \mathrm{~min}$. Red dots represent individual cell cultures $(n=6)$, the horizontal lines in each catseye represent the mean, shaded regions represent standard error of the mean; y-axes use a $\log _{10}$ scale. Black numbers above each set of values (catseye) indicate the ratios of two viral RNA species. $P$ values are calculated for group coefficient using linear regression model. ${ }^{\star *} p<0.01,{ }^{* * *} p<0.001$. g, Spike cleavages of purified virions. USA/WA1-2020, Alpha, Delta, and Delta-P681 viruses were purified and analyzed by Western blot using polyclonal antibodies against spike and anti-nucleocapsid antibodies. Full-length spike (FL), cleaved S1/S2, and S2' proteins were annotated. One representative image of two experiments is shown. $\mathbf{h}$, Quantification of spike processing of different variants from $\mathbf{g}$. Densitometry was performed to quantify the cleavage efficiency of FL spike to S1/S2 subunits using ImageLab 6.0.1. The ratios of S1/S2 over FL were calculated to indicate spike processing efficiencies. The average results 
a

SARS-CoV-2 genome

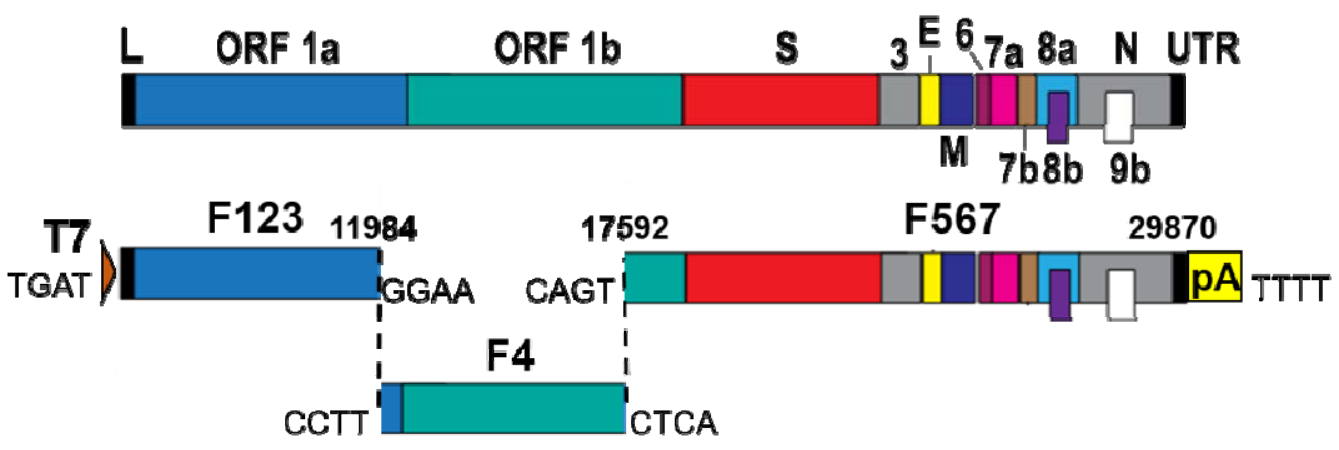

b

\begin{tabular}{|c|c|c|}
\hline Gene & Nucleotide & Amino acid \\
\hline 5'UTR & $\mathrm{C} 241 \mathrm{~T}$ & \\
\hline \multirow[t]{13}{*}{ ORF1ab } & C913T & \\
\hline & C3037T & \\
\hline & C3177T & P971L \\
\hline & C3267T & T1001I \\
\hline & C5388A & A1708D \\
\hline & C5986T & \\
\hline & T6954C & $12230 \mathrm{~T}$ \\
\hline & $\mathrm{T} 8782 \mathrm{C}$ & \\
\hline & $11288-11296$ deletion & SGF $3675-3677$ deletion \\
\hline & $\mathrm{C} 14408 \mathrm{~T}$ & P4715L \\
\hline & $\mathrm{C} 14676 \mathrm{~T}$ & \\
\hline & $\mathrm{C} 15279 \mathrm{~T}$ & \\
\hline & $\mathrm{T} 16176 \mathrm{C}$ & \\
\hline \multirow[t]{9}{*}{ Spike } & 21766-21771 deletion & HV 69-70 deletion \\
\hline & 21991-21993 deletion & Y144 deletion \\
\hline & A23063T & N501Y \\
\hline & $\mathrm{C} 23271 \mathrm{~A}$ & A570D \\
\hline & A23403G & D614G \\
\hline & $\mathrm{C} 23604 \mathrm{~A}$ & $\mathrm{P} 681 \mathrm{H}$ \\
\hline & $\mathrm{C} 23709 \mathrm{~T}$ & T716I \\
\hline & $\mathrm{T} 24506 \mathrm{G}$ & S982A \\
\hline & G24914C & $\mathrm{D} 1118 \mathrm{H}$ \\
\hline \multirow[t]{4}{*}{ ORF8 } & $\mathrm{C} 27972 \mathrm{~T}$ & Q27stop \\
\hline & $\mathrm{G} 28048 \mathrm{~T}$ & R52I \\
\hline & A28111G & Y73C \\
\hline & $\mathrm{C} 28144 \mathrm{~T}$ & S84L \\
\hline \multirow[t]{3}{*}{$\bar{N}$} & 28280 GAT->CTA & D3L \\
\hline & 28881 GGG->AAC & R203K/G204R \\
\hline & C28977T & $\mathrm{S} 235 \mathrm{~F}$ \\
\hline
\end{tabular}
variants. c

\begin{tabular}{|c|c|c|}
\hline Gene & Nucleotide & Amino acid \\
\hline 5'UTR & $\begin{array}{l}\mathrm{C} 210 \mathrm{~T} \\
\mathrm{C} 241 \mathrm{~T}\end{array}$ & \\
\hline ORF1ab & $\begin{array}{l}\text { C1191T } \\
\text { C1267T } \\
\text { C3037T } \\
\text { C5184T } \\
\text { C6539T } \\
\text { T8782C } \\
\text { C9891T } \\
\text { T11418C } \\
\text { T12946C } \\
\text { C14408T } \\
\text { T14444C } \\
\text { G15451A } \\
\text { C16466T } \\
\text { A20262G } \\
\text { C20320T }\end{array}$ & $\begin{array}{l}\text { P1640L } \\
\text { H2092Y } \\
\text { A3209V } \\
\text { V3718A } \\
\text { P4715L } \\
\text { V4727A } \\
\text { G5063S } \\
\text { P5401L } \\
\text { H6686Y }\end{array}$ \\
\hline Spike & $\begin{array}{l}\text { C21618G } \\
\text { G21987A } \\
\text { 22029-22034 deletion } \\
\text { T22917G } \\
\text { C22995A } \\
\text { A23403G } \\
\text { C23604G } \\
\text { G24410A } \\
\text { C24745T }\end{array}$ & $\begin{array}{l}\text { T19R } \\
\text { G142D } \\
\text { E156G/FR 157-158 deletion } \\
\text { L452R } \\
\text { T478K } \\
\text { D614G } \\
\text { P681R } \\
\text { D950N }\end{array}$ \\
\hline ORF3a & $\mathrm{C} 25469 \mathrm{~T}$ & S26L \\
\hline $\mathrm{M}$ & T26767C & $\mathrm{M}: 182 \mathrm{~T}$ \\
\hline ORF7a & $\begin{array}{l}\text { T27638C } \\
\text { C27739T } \\
\text { C27752T }\end{array}$ & $\begin{array}{l}\text { V82A } \\
\text { L116F } \\
\text { T120I }\end{array}$ \\
\hline ORF8 & $\begin{array}{l}\text { C28144T } \\
\text { 28248-28253 deletion }\end{array}$ & $\begin{array}{l}\text { S84L } \\
\text { DF119-120 deletion }\end{array}$ \\
\hline $\mathrm{N}$ & $\begin{array}{l}\text { A28461G } \\
\text { G28881T } \\
\text { G29402T } \\
\text { G29427A }\end{array}$ & $\begin{array}{l}\text { D63G } \\
\text { R203M } \\
\text { D377Y } \\
\text { R385K }\end{array}$ \\
\hline 3'UTR & $\begin{array}{l}\text { G29742T } \\
\text { C29762T }\end{array}$ & \\
\hline
\end{tabular}

Extended Data Figure 1. Construction of infectious cDNA clones for Alpha and Delta

a, Construction of infectious cDNA clones for Alpha and Delta variants. A three-fragment in vitro ligation was performed to construct the full-length cDNA clones of Alpha and Delta SARS-CoV-2. 
466 The construction method was detailed previously. ${ }^{12,13}$ ORFs, the Open reading frames; L, leader 467 sequence; S, spike gene; $\mathrm{E}$, envelope glycoprotein gene; $\mathrm{M}$, membrane glycoprotein gene; $\mathrm{N}$, 468 nucleocapsid gene; UTR, untranslated region. b,c, Mutations from Alpha and Delta variants. 469 The whole genome sequences of Alpha (EPI_ISL_999340) (b) and Delta (EPI_ISL_2100646) (c) were compared to USA/WA1-2020 strain. Nucleotide and amino acid mutations are presented.

471 
a

SARS-CoV-2

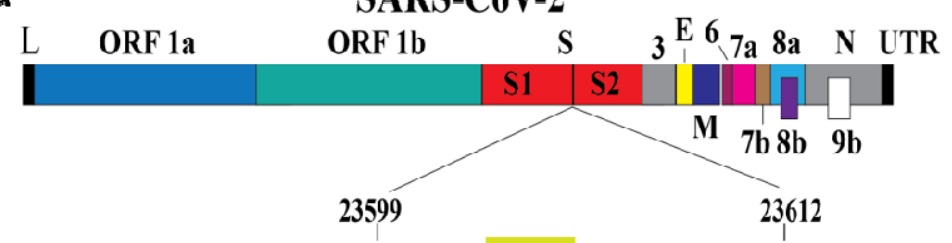

Delta-P681R $\frac{\text { AAT }}{\operatorname{Asn}^{679} \operatorname{Ser}^{680}} \frac{\text { TCT }}{\operatorname{Arg}^{681}} \frac{\text { CGT }}{\operatorname{Arg}^{682}} \underset{\operatorname{Arg}^{683}}{\frac{\text { GCA }}{\text { Ala }^{64}}}$

Delta-P681 AAT TCT CCT CGG CGG GCA

$\mathrm{Asn}^{679} \mathrm{Ser}^{680} \mathrm{Pro}^{681} \operatorname{Arg}^{682} \mathrm{Arg}^{683} \mathrm{Ala}^{684}$

mutation

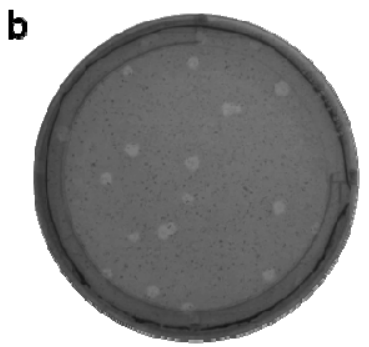

Alpha

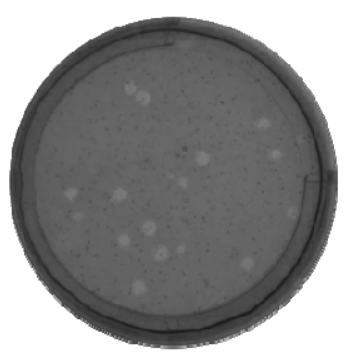

Delta-P681

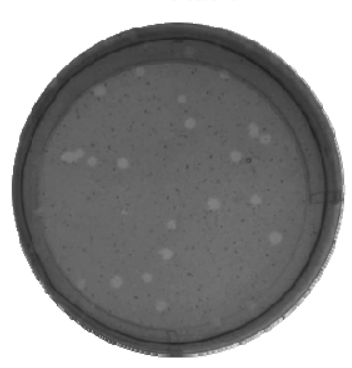

Alpha-splke/Deltabackbone

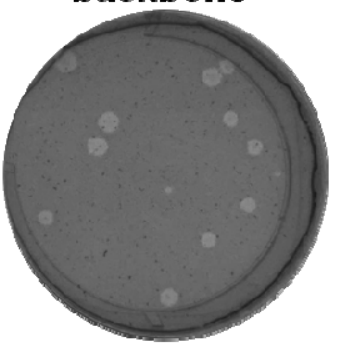

USAWA1-2020

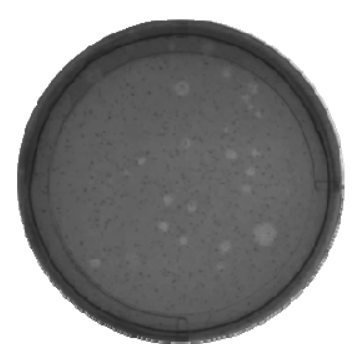

Delta

473 Extended Data Figure 2. Construction of Delta-P681 SARS-CoV-2 and plaque 474 morphologies of different recombinant SARS-CoV-2s.

475 a, Construction of revertant Delta-P681 SARS-CoV-2. Single nucleotide G-to-C substitution was 476 engineered into the Delta variant to construct Delta-P681 SARS-CoV-2. The nucleotide 477 positions of viral genome are annotated. b. Plaque morphologies of Alpha, Alpha-spike/Delta478 backbone, Delta, Delta-P681, and USA-WA1/2020 viruses. The plaque images were taken on 479 day 2.5 post infection of Vero E6 cells. 


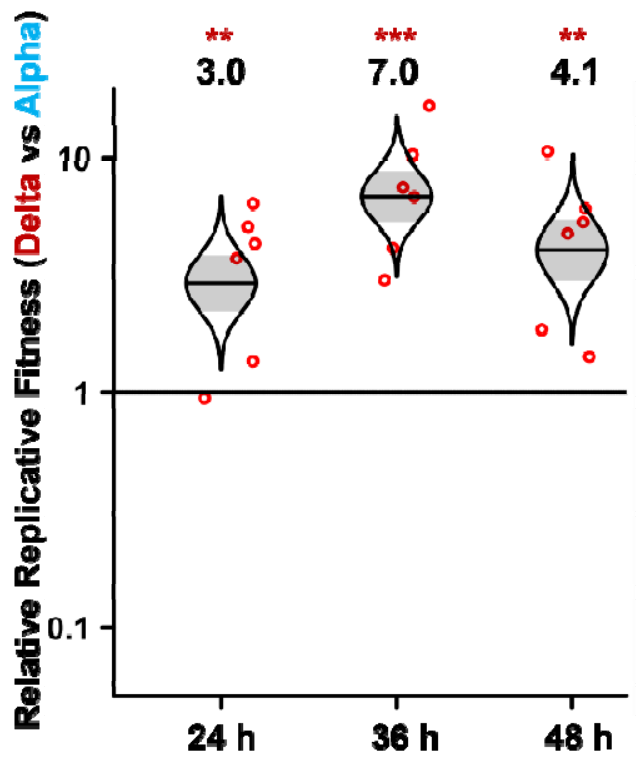

481 Extended Data Figure 3. Viral replication competition between Delta and Alpha variants 482 on Calu-3 cells.

483 Recombinant Delta and Alpha SARS-CoV-2s were mixed in equal PFUs to infect Calu-3 cells at 484 a total MOI of 0.1 . At $2 \mathrm{~h}$ post infection, the cells were washed thrice with DPBS to remove free viruses. Culture medium were sampled for Sanger sequencing at $24 \mathrm{~h}, 36 \mathrm{~h}$, and $48 \mathrm{~h}$ post infection. Red dots represent individual cell cultures $(n=6)$; horizontal lines in each catseye represent the mean; shaded regions represent standard error of the mean; $y$-axes use a $\log _{10}$ scale. Black numbers above each set of values (catseye) indicate the ratios of two viral RNA species. $P$ values are calculated for group coefficient using linear regression model. ${ }^{* *} p<0.01$, ${ }^{\star \star \star} p<0.001$. 
a

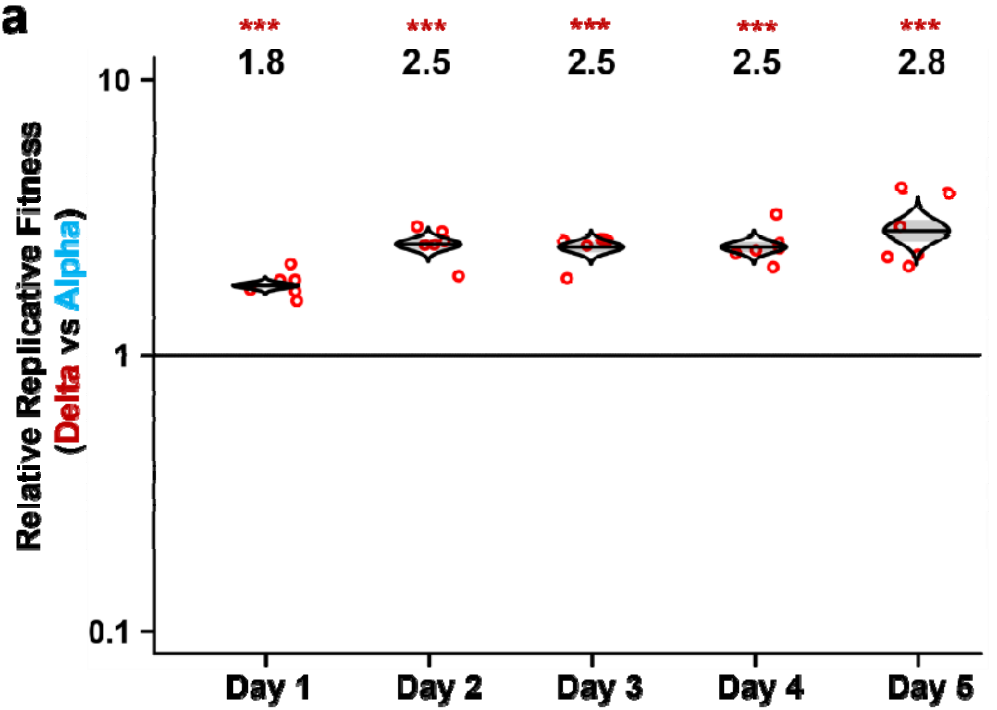

b

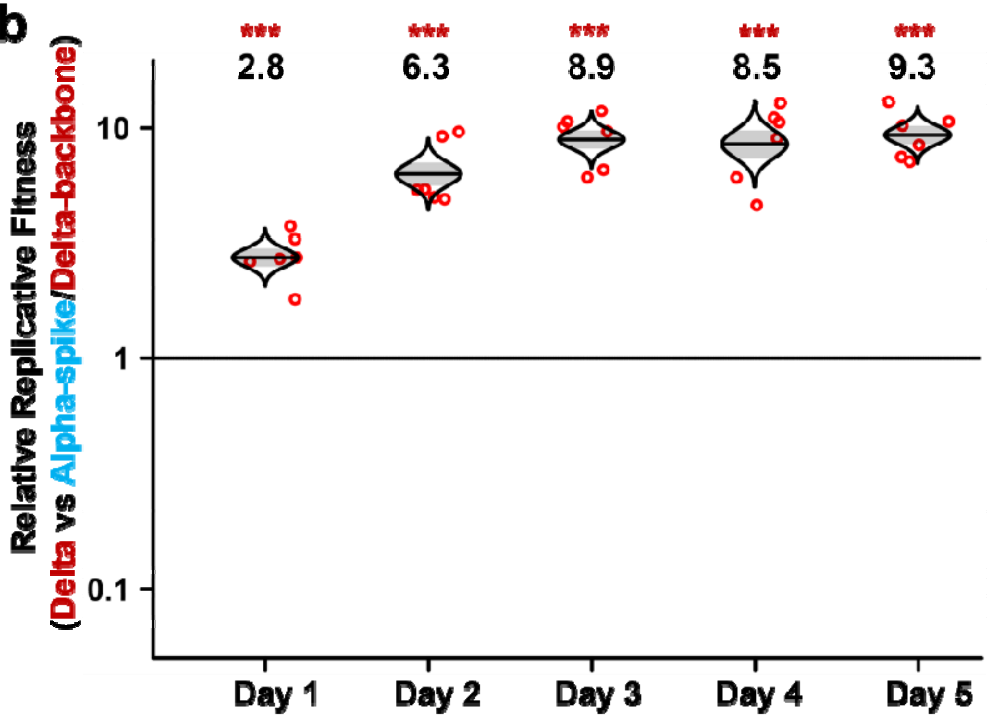

C

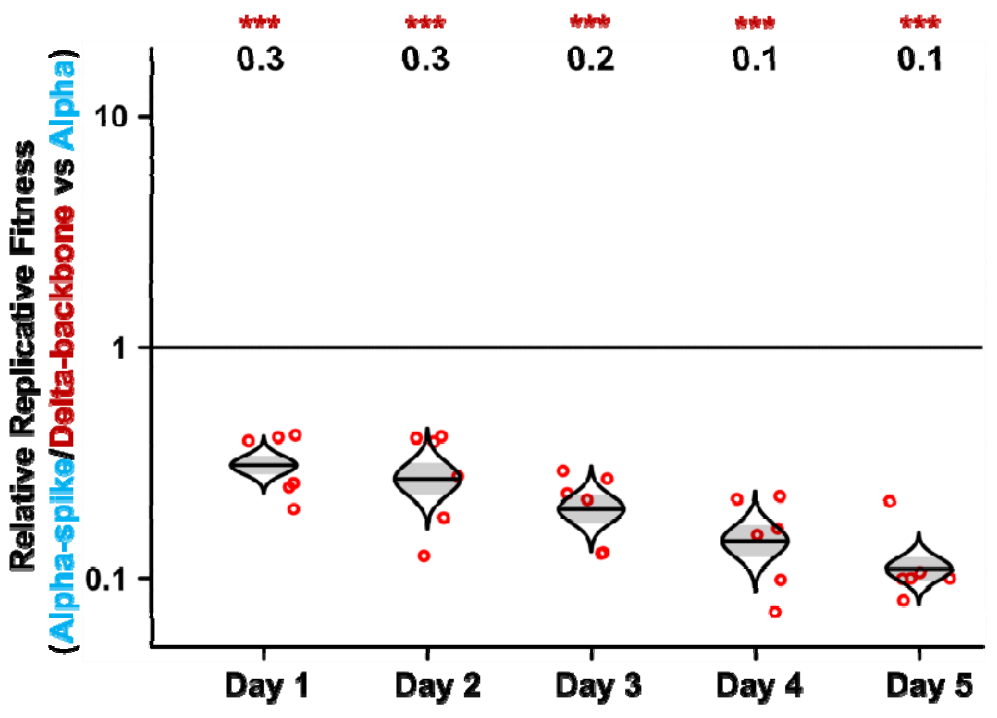


492 Extended Data Figure 4. Validation of viral competition results by next generation 493 sequencing. a-c, RNA samples from competition assays between Delta and Alpha (a), Delta and Alphaspike/Delta-backbone (b), Alpha-spike/Delta-backbone and Alpha (c) were initially assessed using Sanger sequencing (Fig. 1b-d). The same RNA samples were retested here using next generation sequencing (NGS). Red dots represent individual cell cultures $(n=6)$; the horizontal lines in each catseye represent the mean; shaded regions represent standard error of the mean; $y$-axes use a $\log _{10}$ scale. Black numbers above each set of values (catseye) indicate the relative

501 fitness estimates. $P$ values are calculated for group coefficient using linear regression model. ${ }^{* * *} p<0.001$. 
a

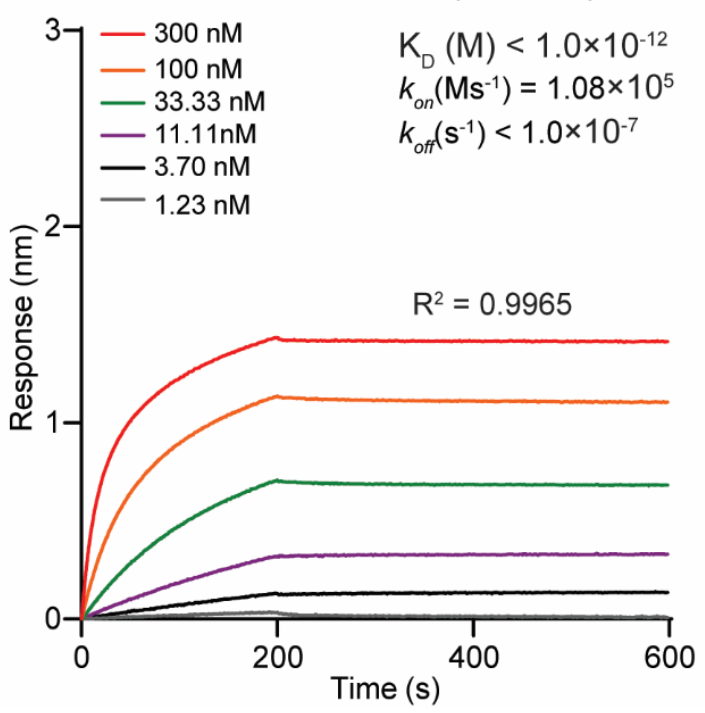

b

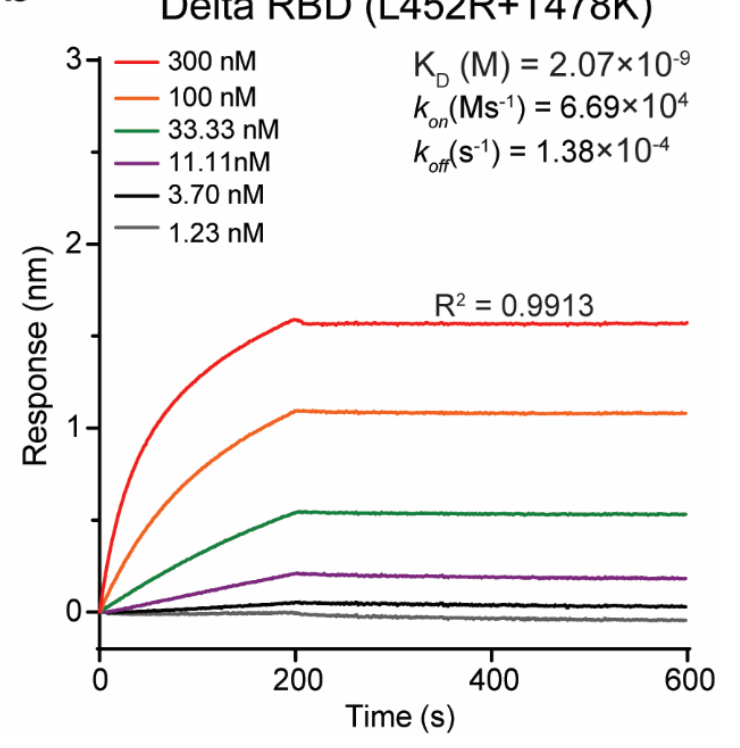
receptor. biosensors were then dipped into serially diluted human ACE2 protein and buffers to measure the association and dissociation kinetics. The binding affinity-related parameters, including association $\left(\mathrm{K}_{\mathrm{on}}\right)$, dissociation $\left(\mathrm{K}_{\mathrm{off}}\right)$, and affinity $\left(\mathrm{K}_{\mathrm{D}}\right)$ are shown. The affinity of ACE2 to Alpha $\operatorname{RBD}\left(\mathrm{N} 501 \mathrm{Y}\right.$ ) is below the detection limit and is presented as $<1.0 \times 10^{-12}$. The result for Alpha 


\section{Extended Data Table 1. Primer list used for SARS-CoV-2 infectious clones construction,} 513 RT-PCR and sequencing.

\begin{tabular}{|c|c|c|}
\hline $\begin{array}{l}\text { Construction of Alpha full } \\
\text { length and Alpha-backbone } \\
\text { infectious clone }\end{array}$ & Forward primer & Reverse primer \\
\hline $\mathrm{C} 241 \mathrm{~T}$ & atctaggtttTgtccgggtgtgaccgaaag & ctttcggtcacacccggacAaaacctagat \\
\hline C913T & tgcactttgtcTgaacaactggactt & aagtccagttgttcAgacaaagtgca \\
\hline C3037T & gtattgttctttTtaccctccagatgagg & cctcatctggagggtaAaaagaacaatac \\
\hline C3177T & ctgctcttcaacTtgaagaagagcaa & ttgctcttcttcaAgttgaagagcag \\
\hline С3267T & cagacaactaTtattcaaacaattgttgagg & cctcaacaattgtttgaataAtagttgtctg \\
\hline C5388A & ggctggtgaagctgAtaacttttgtgc & gcacaaaagttaTcagcttcaccagcc \\
\hline C5986T & attcttatttTacagagcaaccaattg & caattggttgctctgtAaaataagaat \\
\hline T6954C & gataaatattaCaatttggttttac & gtaaaaaccaaattGtaatatttatc \\
\hline $11288-11296 \mathrm{del}$ & gatactagtttgaagctaaaagactgtgt & acacagtcttttagcttcaaactagtatc \\
\hline $\mathrm{C} 14408 \mathrm{~T}$ & tacagtgttcccacTtacaagttttggacc & ggtccaaaacttgtaAgtgggaacactgta \\
\hline $\mathrm{C} 14676 \mathrm{~T}$ & gtcaaaccTggtaattttaacaaag & ctttgttaaaattaccAggtttgac \\
\hline C15279T & gaaaaccctcaTcttatgggttgggat & atcccaacccataagAtgagggttttc \\
\hline T16176C & ctaatgataacacCtcaaggtattggga & tcccaataccttgaGgtgttatcattag \\
\hline C27972T/G28048T & $\begin{array}{l}\text { cttaacatcaaccatatgtagttgatgacccgtgtcctattc } \\
\text { acttcta }\end{array}$ & $\begin{array}{l}\text { ttatagctcctactctaatataccatttagaatagaagtgaata } \\
\text { ggaca }\end{array}$ \\
\hline A28111G/C28144T & $\begin{array}{l}\text { cagtgcatcgatatcggtaattatacagtttcctgtttaccttt } \\
\text { tac }\end{array}$ & $\begin{array}{c}\text { gtaaaaggtaaacaggaaactgtataattaccgatatcgat } \\
\text { gcactg }\end{array}$ \\
\hline $\begin{array}{c}\text { A28271del/28280-28282GAT- } \\
\text { CTA }\end{array}$ & caaactaaatgtctctaaatggaccccaaaatcagcg & cgctgattttggggtccatttagagacatttagtttg \\
\hline 28881-28883GGG-AAC & caactccaggcagcagtaaacgaacttctcctgc & gcaggagaagttcgtttactgctgcctggagttg \\
\hline C28977T & tgagagcaaaatgtttggtaaaggccaaca & tgttggcctttaccaaacattttgctctca \\
\hline Alpha-F123-F1 & $\begin{array}{c}\text { cattatacgaagttatattcgatgcggccgctaatacgact } \\
\text { cactatagattaaag }\end{array}$ & gggccgacaacatgaagacagtg \\
\hline Alpha-F123-F2 & acactgtcttcatgttgtcggcccaaatgttaacaaag & ctattacgtttgtaacacatcatacaTgtAgatgaattac \\
\hline Alpha-F123-F3 & gtatgatgtgttacaaacgtaatagagcaacaagag & $\begin{array}{l}\text { aggtcgactctagaggatcccacATCGAtggtctcaaag } \\
\text { gcttcagtagtatctttagc }\end{array}$ \\
\hline Alpha-F4 & tgtagaaaacccagatatatt & caaaacactctacacgagcac \\
\hline Alpha-F567-F1 & $\begin{array}{c}\text { tatacgaagttatattcgatgcggccgcgtctcagagtgct } \\
\text { ttggtttatgataataag }\end{array}$ & cttttgttgtataaacccacaaatg \\
\hline Alpha-F567-F2 & catttgtgggtttatacaacaaaag & caatcaagccagctataaaacc \\
\hline Alpha-F567-F3 & ggtttatagctggcttgattg & cgaggcttcttagaagcctca \\
\hline Alpha-backbone-F567-F1 & $\begin{array}{c}\text { tatacgaagttatattcgatgcggccgcgtctcagagtgct } \\
\text { ttggtttatgataataag }\end{array}$ & cttttgttgtataaacccacaaatg \\
\hline Alpha-backbone-F567-F2 & catttgtgggtttatacaacaaaag & caatcaagccagctataaaacc \\
\hline Alpha-backbone-F567-F3 & ggtttatagctggcttgattg & cgaggcttcttagaagcctca \\
\hline
\end{tabular}




\begin{tabular}{|c|c|c|}
\hline $\begin{array}{l}\text { Construction of Delta full } \\
\text { length and Delta-backbone } \\
\text { infectious clone }\end{array}$ & Forward primer & Reverse primer \\
\hline C210T & GTTTCGTCCGTTTTGCAGCCGATCATC & GATGATCGGCTGCAAAACGGACGAAAC \\
\hline $\mathrm{C} 241 \mathrm{~T}$ & $\begin{array}{c}\text { ATCTAGGTTTTGTCCGGGTGTGACCGA } \\
\text { AAG }\end{array}$ & $\begin{array}{c}\text { CTTTCGGTCACACCCGGACAAAACCTAG } \\
\text { AT }\end{array}$ \\
\hline C1191T & $\begin{array}{c}\text { CCAGTTGCGTCACTAAATGAATGCAAC } \\
\text { C }\end{array}$ & GGTTGCATTCATTTAGTGACGCAACTGG \\
\hline C1267T & GGCAGACGGGTGATTTTGTTAAAGCC & GGCTTTAACAAAATCACCCGTCTGCC \\
\hline C3037T & $\begin{array}{r}\text { GTATTGTTCTTTTTACCCTCCAGATGAG } \\
\text { G }\end{array}$ & $\begin{array}{c}\text { CCTCATCTGGAGGGTAAAAAGAACAATA } \\
\text { C }\end{array}$ \\
\hline C5184T & $\begin{array}{c}\text { ACACAACTGATCTTAGTTTTCTGGGTA } \\
\text { G }\end{array}$ & CTACCCAGAAAACTAAGATCAGTTGTGT \\
\hline C6539T & GAGGTTGGCTACACAGATCTAATGGC & GCCATTAGATCTGTGTAGCCAACCTC \\
\hline T8782C & $\begin{array}{c}\text { ACACATGGTTTAGCCAGCGTGGTGGTA } \\
\text { G }\end{array}$ & CTACCACCACGCTGGCTAAACCATGTGT \\
\hline C9891T & $\begin{array}{r}\text { GATACTTAGTTCTTTATAATAAGTACAA } \\
\text { G }\end{array}$ & CTTGTACTTATTATAAAGAACTAAGTATC \\
\hline $\mathrm{T} 11418 \mathrm{C}$ & $\begin{array}{l}\text { CTTGACACTCGCTTATAAAGTTTATTAT } \\
\text { GG }\end{array}$ & $\begin{array}{c}\text { CCATAATAAACTTTATAAGCGAGTGTCAA } \\
\text { G }\end{array}$ \\
\hline T12946C & $\begin{array}{c}\text { GGTCCTAAAGTGAAGTACTTATACTTTA } \\
\text { TT }\end{array}$ & $\begin{array}{c}\text { AATAAAGTATAAGTACTTCACTTTAGGAC } \\
\text { C }\end{array}$ \\
\hline $\mathrm{C} 14408 \mathrm{~T}$ & $\begin{array}{c}\text { TACAGTGTTCCCACTTACAAGTTTTTGGA } \\
\text { CC }\end{array}$ & $\begin{array}{c}\text { GGTCCAAAACTTGTAAGTGGGAACACTG } \\
\text { TA }\end{array}$ \\
\hline T14444C & $\begin{array}{c}\text { GTGAGAAAAATATTTGCTGATGGTGTT } \\
\text { CCA }\end{array}$ & $\begin{array}{c}\text { TGGAACACCATCAGCAAATATTTTTCTCA } \\
\text { C }\end{array}$ \\
\hline G15451A & $\begin{array}{c}\text { GGTCATGTGTGGCAGTTCACTATATGT } \\
\mathrm{T}\end{array}$ & AACATATAGTGAACTGCCACACATGACC \\
\hline $\mathrm{C} 16466 \mathrm{~T}$ & $\begin{array}{l}\text { GTAAATCACATAAACTACCCATTAGTTT } \\
\text { TCC }\end{array}$ & $\begin{array}{c}\text { GGAAAACTAATGGGTAGTTTATGTGATTT } \\
\text { AC }\end{array}$ \\
\hline A20262G & $\begin{array}{c}\text { GGAAATTGATTTCTTGGAATTAGCTATG } \\
\text { G }\end{array}$ & CCATAGCTAATTCCAAGAAATCAATTTCC \\
\hline C20320T & GCTATGCCTTCGAATATATCGTTTATGG & CCATAAACGATATATTCGAAGGCATAGC \\
\hline C21618G & GTGTGTTAATCTTAGAACCAGAACTC & GAGTTCTGGTTCTAAGATTAACACAC \\
\hline G21987A & GATCCATTTTTGGATGTTTATTACCAC & GTGGTAATAAACATCCAAAAATGGATC \\
\hline 22029-22034 deletion & $\begin{array}{c}\text { GAAAGTGGAGTTTATTCTAGTGCGAAT } \\
\text { AATTGC }\end{array}$ & $\begin{array}{c}\text { ATAAACTCCACTTTCCATCCAACTTTTGT } \\
\text { TGTT }\end{array}$ \\
\hline T22917G & $\begin{array}{c}\text { GGTGGTAATTATAATTACCGGTATAGAT } \\
\text { TGTTTAGG }\end{array}$ & $\begin{array}{c}\text { CCTAAACAATCTATACCGGTAATTATAAT } \\
\text { TACCACC }\end{array}$ \\
\hline C22995A & GGCCGGTAGCAAACCTTGTAATGGTG & CACCATTACAAGGTTTGCTACCGGCC \\
\hline A23604G & $\begin{array}{c}\text { GACTAATTCTCGTCGGCGGGCACGTA } \\
\text { GTGT }\end{array}$ & $\begin{array}{c}\text { ACACTACGTGCCCGCCGACGAGAATTAG } \\
\text { TC }\end{array}$ \\
\hline G24410A & GGAAAACTTCAAAATGTGGTCAACC & GGTTGACCACATTTTTGAAGTTTTCC \\
\hline $\mathrm{C} 24745 \mathrm{~T}$ & $\begin{array}{c}\text { CTCATGGTGTAGTTTTCTTGCATGTGA } \\
\text { C }\end{array}$ & GTCACATGCAAGAAAACTACACCATGAG \\
\hline C25469T & GATGCTACTCCTTTAGATTTTGTTCGCG & CGCGAACAAAATCTAAAGGAGTAGCATC \\
\hline T26767C & $\begin{array}{c}\text { CCGGTGGAATTGCTACCGCAATGGCTT } \\
\text { G }\end{array}$ & CAAGCCATTGCGGTAGCAATTCCACCGG \\
\hline T27638C & $\begin{array}{c}\text { CGTGCCAGATCAGCTTCACCTAAACTG } \\
\mathrm{T}\end{array}$ & ACAGTTTAGGTGAAGCTGATCTGGCACG \\
\hline C27739T/C27752T & $\begin{array}{c}\text { TCAAAAGAAAGATAGAATGATTGAACTT } \\
\text { TCA }\end{array}$ & $\begin{array}{c}\text { CATTCTATCTTTCTTTTGAATGTGAAGCA } \\
\text { AAGTG }\end{array}$ \\
\hline $\mathrm{C} 28144 \mathrm{~T}$ & $\begin{array}{l}\text { TCGGTAATTATACAGTTTCCTGTTTACC } \\
\text { TTTTAC }\end{array}$ & $\begin{array}{l}\text { GTAAAAGGTAAACAGGAAACTGTATAATT } \\
\text { ACCGA }\end{array}$ \\
\hline
\end{tabular}


bioRxiv preprint doi: https://doi.org/10.1101/2021.08.12.456173; this version posted September 5,2021 . The copyright holder for this preprint (which was not certified by peer review) is the author/funder, who has granted bioRxiv a license to display the preprint in perpetuity. It is made available under aCC-BY-NC-ND 4.0 International license.

Delta-F123-F2

\begin{tabular}{|c|c|c|}
\hline RT-PCR for NGS & Forward primer & Reverse primer \\
\hline Delta vs Alpha & ggttttaattgttactttcctttaca & aagaacacctgtgcctgtt \\
\hline $\begin{array}{l}\text { Alpha-spike/Delta-backbone vs } \\
\text { Alpha }\end{array}$ & acagtgttcccacctacaagt & ccagaagcagcgtgcatagc \\
\hline $\begin{array}{c}\text { Delta vs Alpha-spike/Delta- } \\
\text { backbone }\end{array}$ & ggttttaattgttactttcctttaca & aagaacacctgtgcctgtt \\
\hline Sanger sequencing & Forward primer & \\
\hline Delta vs Delta-P681 & aggatgttaactgcacaga & \\
\hline Delta-P681 vs Alpha & aggatgttaactgcacaga & \\
\hline Delta vs Alpha & gattgctgattataattata & \\
\hline $\begin{array}{l}\text { Alpha-spike/Delta-backbone vs } \\
\text { Alpha }\end{array}$ & gttgacactgacttaacaaagcc & \\
\hline $\begin{array}{c}\text { Delta vs Alpha-spike/Delta- } \\
\text { backbone }\end{array}$ & gattgctgattataattata & \\
\hline
\end{tabular}

28248-28253 deletion

28271 deletion

A28461G

G28881T

G29402T/G29427A

G29742T/C29762T

Delta-F123-F1

Delta-F4

Delta-F567

Delta-backbone-F567-F1

Delta-backbone-F567-F2

Delta-backbone-F567-F3

\begin{tabular}{c}
$\begin{array}{c}\text { RT-PCR for Sanger } \\
\text { sequencing }\end{array}$ \\
\hline Delta vs Delta-P681 \\
Delta-P681 vs Alpha \\
Delta vs Alpha
\end{tabular}

Alpha-spike/Delta-backbone vs Alpha

Delta vs Alpha-spike/Deltabackbone

GACGTTCGTGTTGTTTTAATCTAAACGA ACAAACT

GAACAAACTAAATGTCTGATAATGGAC CCC

CATGGCAAGGAAGGCCTTAAATTCCCT $\mathrm{C}$

TCCAGGCAGCAGTATGGGAACTTCTCC TGC

GCTTATGAAACTCAAGCCTTACCGCAG
AAACAGAAGAAAC

CACTCGGAGTACGATCGAGTGTATAGT GAACAAT

cattatacgaagttatattcgatgcggccgctaatacgact cactatagattaaag

acactgtcttcatgttgtcggcccaaatgttaacaaag

cctcttacaacagcagccaaact

tatacgaagttatattcgatgcggccgcgtctcagagtgct ttggtttatgataataag

tatacgaagttatattcgatgcggccgcgtctcagagtgct ttggtttatgataataag

catttgtgggtttatacaacaaaag

ggtttatagctggcttgattg

Forward primer

tccacttttaagtgttatggag

tccacttttaagtgttatggag

tccacttttaagtgttatggag

tgtagaaaacccagatatatt

tccactttraagtgttatggag

514

515 AACGTC

GGGGTCCATTATCAGACATTTAGTTTGTT

C

GAGGGAATTTAAGGCCTTCCTTGCCATG

GCAGGAGAAGTTCCCATACTGCTGCCTG GA

GTTTCTGCGGTAAGGCTTGAGTTTCATAA GCCTTCTTCTT

ACTATACACTCGATCGTACTCCGAGTGG CCTCGG

gggccgacaacatgaagacagtg

aggtcgactctagaggatcccacATCGAtggtctcaaag gcttcagtagtatctttagc

caaaacactctacacgagcac

caaacatgagaattggtcgacggccc

cttttgttgtataaacccacaaatg

caatcaagccagctataaaacc

cgaggcttcttagaagcctca

\section{Reverse primer}

gttaaagcacggtttaattgtg

gttaaagcacggtttaattgtg

gttaaagcacggtttaattgtg

tggaaaaccagctgatttgtc

gttaaagcacggtttaattgtg

\section{Reverse primer}

AGTTTGTTCGTTTAGATTAAAACAACACG 
Extended Data Table 2. The input and output viral RNA ratios in competition assays detected by sanger sequencing.

\begin{tabular}{|c|c|c|c|c|c|c|}
\hline \multirow{2}{*}{ Groups } & \multicolumn{3}{|c|}{ HAE } & \multicolumn{3}{|c|}{ Calu-3 } \\
\hline & Days & $\begin{array}{l}\text { Input } \\
\text { ratio }\end{array}$ & $\begin{array}{l}\text { Output } \\
\text { ratio }\end{array}$ & Hours & $\begin{array}{l}\text { Input } \\
\text { ratio }\end{array}$ & $\begin{array}{l}\text { Output } \\
\text { ratio }\end{array}$ \\
\hline \multirow{5}{*}{ Delta vs Alpha } & Day 1 & 1.24 & 2.10 & $24 \mathrm{~h}$ & 1.53 & 4.56 \\
\hline & Day 2 & 1.24 & 3.24 & $36 \mathrm{~h}$ & 1.53 & 10.65 \\
\hline & Day 3 & 1.24 & 3.17 & $48 \mathrm{~h}$ & 1.53 & 6.21 \\
\hline & Day 4 & 1.24 & 3.51 & & & \\
\hline & Day 5 & 1.24 & 3.78 & & & \\
\hline \multirow{5}{*}{$\begin{array}{c}\text { Delta vs Alpha- } \\
\text { spike/Delta-backbone }\end{array}$} & Day 1 & 1.07 & 2.97 & & & \\
\hline & Day 2 & 1.07 & 6.93 & & & \\
\hline & Day 3 & 1.07 & 10.60 & & & \\
\hline & Day 4 & 1.07 & 9.64 & & & \\
\hline & Day 5 & 1.07 & 10.53 & & & \\
\hline \multirow{5}{*}{$\begin{array}{l}\text { Alpha-spike/Delta- } \\
\text { backbone vs Alpha }\end{array}$} & Day 1 & 1.45 & 0.59 & & & \\
\hline & Day 2 & 1.45 & 0.46 & & & \\
\hline & Day 3 & 1.45 & 0.28 & & & \\
\hline & Day 4 & 1.45 & 0.22 & & & \\
\hline & Day 5 & 1.45 & 0.15 & & & \\
\hline \multirow{5}{*}{ Delta vs Delta-P681 } & Day 1 & 0.95 & 2.05 & & & \\
\hline & Day 2 & 0.95 & 2.20 & & & \\
\hline & Day 3 & 0.95 & 2.38 & & & \\
\hline & Day 4 & 0.95 & 2.77 & & & \\
\hline & Day 5 & 0.95 & 3.25 & & & \\
\hline \multirow{5}{*}{ Delta-P681 vs Alpha } & Day 1 & 1.51 & 1.33 & & & \\
\hline & Day 2 & 1.51 & 1.13 & & & \\
\hline & Day 3 & 1.51 & 1.21 & & & \\
\hline & Day 4 & 1.51 & 0.97 & & & \\
\hline & Day 5 & 1.51 & 0.85 & & & \\
\hline
\end{tabular}

